MATEC Web of Conferences 25, 02008

(2015)

DOI: $10.1051 /$ matecconf/ 20152502008

(C) Owned by the authors, published by EDP Sciences, 2015

\title{
Experimental Study on the Fractal Characteristics of Rocks Crushing
}

\author{
Gaipin Cai*, Yang Xiong \& Longfei Lin \\ School of Mechanical and Electrical Engineering, Jiangxi University of Science and Technology, Ganzhou, \\ Jiangxi, China
}

\begin{abstract}
A fractal model for the size distribution was proposed based on the fractal character of the crushing granularity of rocks. The crushing tests of three different rocks were conducted. And the test results of rock size distribution were used to conduct a statistical analysis. The results indicate that the fractal characteristics of rock are universal. The fractal dimension is one of perfect indicators to evaluate crushing, reflecting the whole process of the rock crushing. Subsequently, the relationship between fractal dimension and both of size of rock and energy consumption is established. It gives a better explanation from the aspect of mechanism. What's more, the fractal dimension represents the effect and the rule of the size distribution of crushing and provides a theoretical foundation for controlling the size distribution of rock.
\end{abstract}

Keywords: fractal dimension; size distribution; crushing test; broken indicators

\section{INTRODUCTION}

Since the 1970 s, fractal theory as a study of the irregular geometrical shape was put forward by a French mathematician Mandelbort. At present, this theory was widely used in the physical, metallurgy, mining, materials, computer graphics, and other fields ${ }^{[1]}$. Because the rock after crushing has good fractal structure, the fractal theory has been widely used on the rock mechanics. According to the theory, the rock particle size, uniform degree was respectively described by the broken fractal dimension. At present, some basic theories have been established in the rock crushing, particle size distribution ${ }^{[2]}$, energy consumption and other respects.

With the rapid development of modern experiment techniques and advanced computer technology, the research and analysis of fractal theory in the field of broken becomes possible. This provides the corresponding theoretical and practical significance for the better research of rock crusher. This particle size distribution of the crushed rock ore is an important indicator of the crushing effect, which directly affects the economic benefits of some enterprises. According to the rock block distribution of fractal characteristics, Xie $\mathrm{H}^{[3]}$, the peak ${ }^{[4]}$ and Wang $\mathrm{Li}^{[5]}$ proposed a method to predict the particle size distribution after the study of crushed ore and rock fragmentation. $\mathrm{Wu}$ Xianzhen et al. ${ }^{[6]}$ explored the crushing process of acoustic emission by using fractal characteristic sequence of rock failure process of acoustic emission.

Fractal dimension D can reflect the statistical evolution of rock internal micro gap. A.Tasdemir ${ }^{[7]}$ evaluated the fractal characteristics of particle size distribution of Jaw crusher, cone crusher, hammer crusher and the ball mill equipment. The result indicates that the particle size distribution of chromite have fractal rule and the range of fractal dimension are different. $\mathrm{Xu}$ Jinyu et al. ${ }^{[8]}$ analyzed fragmentation of rock by using fractal geometry approach after the shock loading on the marble fractal geometry test. The rock crushing process was conducted a quantitative description. Wang Li et al. ${ }^{[9]}$ proposed the methods to establish a damage model according to the self-similarity after the fragmentation of rock. The rock fracture damage parameter was defined according to the distribution of rock fragmentation. Liu Yu $[10,11]$ established an impact crusher coal particle size analysis model according to the fractal theory, which can do a good description of the impact of coal particle size distribution after crushing. The fractal dimension can do a good evaluation of the impact of coal crushing effect.

In this paper, the test study on the impact indicators broke (the average particle size, the yield of fine-sized particles and the crushing ratio) relationships between the fractal dimension through the experiment of Niobium tantalum ore, granite and cobbles. The analysis about the relationship among the fractal dimension and the both broken rock particle size and energy consumption is obtained according to the particle size distribution.

\section{BROKEN CALCULUS D DIMENSION}

According to the basic definition of fractals by ${ }^{[12]}$ and the material after crushing its fractal size, experts can use different fractal dimensions to represent its characteristics. For example, as shown ${ }^{[13]}$ in Katz formula:

$$
V_{\left(\delta<d_{i}\right)}=A\left(\frac{\overline{d_{i}}}{d_{\max }}\right)^{3-D}
$$

*Corresponding author: cgp4821@yahoo.com.cn

This is an Open Access article distributed under the terms of the Creative Commons Attribution License 4.0, which permits unrestricted use, distribution, and reproduction in any medium, provided the original work is properly cited. 


\section{MATEC Web of Conferences}

Where: $V_{\left(\delta<d_{i}\right)}$ represents one which is less than the size of the volume $d_{i} ; A$ is the form factor of particles; $D$ is the particle fractal dimension; $\bar{d}_{i}$ represents the average value of grain size in between; $d_{\text {max }}$ represents the maximum particle size after crushing (mm).

By Equation (1), it shows that the mass distribution of the crushed rock can be expressed as:

$$
M_{\left(\delta<\overline{d_{i}}\right)}=\rho V_{\left(\delta<\overline{d_{i}}\right)}=\rho A\left(\frac{\overline{d_{i}}}{d_{\max }}\right)^{3-D}
$$

Where: $M_{\left(\delta<d_{i}\right)}$ is the crushed rock mass distribution; $\rho$ is the density of rock.

Assuming that the total mass of rock is $M_{T}$, so:

$$
M_{T}=\lim _{i \rightarrow \infty} M_{\left(\delta<\overline{d_{i}}\right)}=\rho A
$$

Simultaneously, divide (2) by (3) to obtain the used particle size which is less than $\bar{d}_{i}$, a minute quality dimension which represents the cumulative probability:

$$
\frac{M_{\left(\delta<\bar{d}_{i}\right)}}{M_{T}}=\left(\frac{\bar{d}_{i}}{d_{\max }}\right)^{3-D}
$$

By Formula (4), we obtained the logarithmic transformation:

$$
\begin{aligned}
& \ln \left(\frac{M_{\left(\delta<\bar{d}_{i}\right)}}{M_{T}}\right)=(3-\mathrm{D}) \ln \left(\frac{\bar{d}_{i}}{d_{\max }}\right) \\
& \text { With } \ln \left(\frac{M_{\left(\delta<\bar{d}_{i}\right)}}{M_{T}}\right) \text { and } \ln \left(\frac{\bar{d}_{i}}{d_{\max }}\right) \text { being ordinate }
\end{aligned}
$$

and abscissa respectively, the experimental data were analyzed according to the fitting whose slope is $K$. Then its subsize fractal dimension $D$ is $3-K$.

\section{ROCK CRUSHING SQUEEZE TEST PROGRAM}

The rock crushing squeeze test equipment is shown in Figure 1. This equipment is composed of motor, reducer, feed plate and roller. When rollers are smoothly ran in the motor drive, the feed conveyor rollers will squeeze the rock crushing and collect data by using wireless torque sensor.

The broken evaluation is estimated to quantify the broken amount in the actual production. The situation of rock crushing is used to adjust the crushing equipment according to the requirement of production in real time ${ }^{[14]}$. Commonly-used indicators are the bro- ken average particle size, the fine-sized particles yield and the broken rate. For the same external conditions, the rock crushing process and the fractal characteristics of crushed rock granularity have a certain relationship with attributes themselves. And for different types of rock particles size multilevel control experiments, it is necessary to let the board crusher be under the same working condition. In this paper, we use three different kinds of rock to conduct the crushing squeeze tests, and the tantalum-niobium ore with five different particle sizes is used to conduct the squeeze crushing experiments.

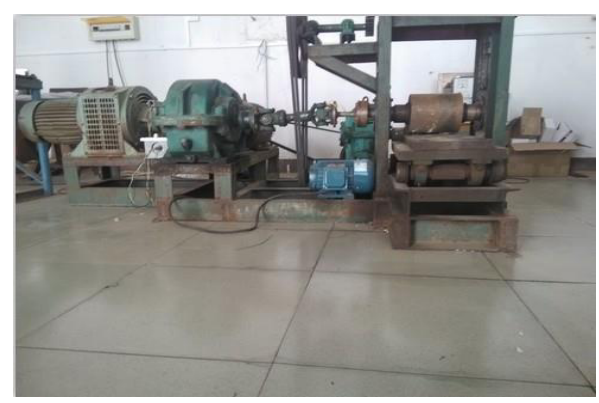

Figure 1. Experimental equipment for crushing

\section{ANALYSIS OF TEST RESULTS}

In order to study the particle size distribution characteristics of crushed rock, we explore whether the fractal dimension can be used as indicators to evaluate the crushing ratio of rock. In this paper, we respectively squeeze and crush three kinds of rock such as the tantalum and niobium ore, granite and pebble, and the crushed forms thereof are shown in Figure 2. Through using a standard sieve, the size of rock particles is divided into five grades, including $+11 \mathrm{~mm}$, the range of $8-11 \mathrm{~mm}$, the range of $5-8 \mathrm{~mm}$, the range of $2-5 \mathrm{~mm}$ and $-2 \mathrm{~mm}$. The amount of quality product in each class on the screen and the record of experimental data are shown in Table 1.

\subsection{Particle size distribution of rock crushing squeeze}

The size distribution of three kinds of different rocks after being squeezed and crushed is shown in Figure 3 and Table 1 .

Figure 3 shows the different rocks under the same condition due to different properties and fragmentation of distribution. By comparing the experimental data after crushed, the results indicates that cobblestone have a large percentage of total quality large particle mass and uneven particle size distribution. However, the $\mathrm{Ta}-\mathrm{Nb}$ ore particles after crushed have the largest group of fine particles and few large particles. The amount of fine particles granite is between that of the cobblestone and the $\mathrm{Ta}-\mathrm{Nb}$ ore. This is because the cobblestone with highest hardness has the 


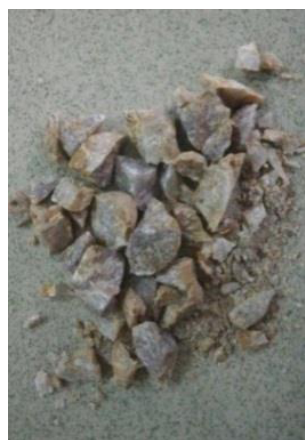

(a) Cobblestone

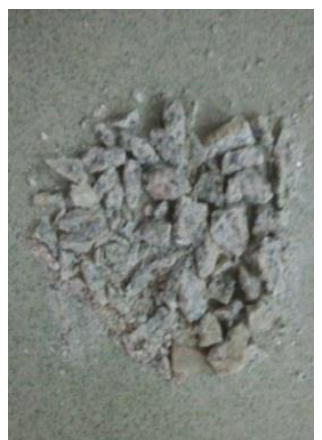

(b) Granite

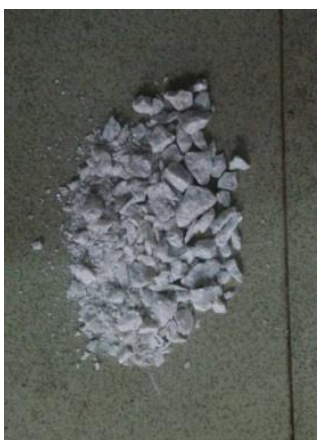

(c) $\mathrm{Ta}-\mathrm{Nb}$ ore

Figure 2. Broken forms of different rocks

Table 1. Size distribution of rock

\begin{tabular}{lllllll}
\hline \multirow{2}{*}{ Experiment No. } & \multicolumn{5}{c}{ Particle mass distribution/g } \\
\cline { 2 - 7 } & $>11 \mathrm{~mm}$ & $11-8 \mathrm{~mm}$ & $8-5 \mathrm{~mm}$ & $5-2 \mathrm{~mm}$ & $<2 \mathrm{~mm}$ & Total \\
\hline 1(Cobblestone) & 27.6 & 16.3 & 6.7 & 3.3 & 2.0 & 55.9 \\
& 0.494 & 0.292 & 0.120 & 0.059 & 0.036 & 1 \\
2(Granite) & 18 & 15.9 & 11.2 & 5.2 & 3.8 & 54.1 \\
& 0.33 & 0.29 & 0.21 & 0.096 & 0.07 & 1 \\
3 (Ta-Nb ore) & 14 & 14.9 & 10.2 & 7.9 & 5.1 & 52.1 \\
& 0.269 & 0.286 & 0.196 & 0.152 & 0.098 & 1 \\
\hline
\end{tabular}

largest resistance to avoid being crushed. However, the tantalum-niobium ore with low hardness and being brittle will be more easily crushed when broken into many small particles.

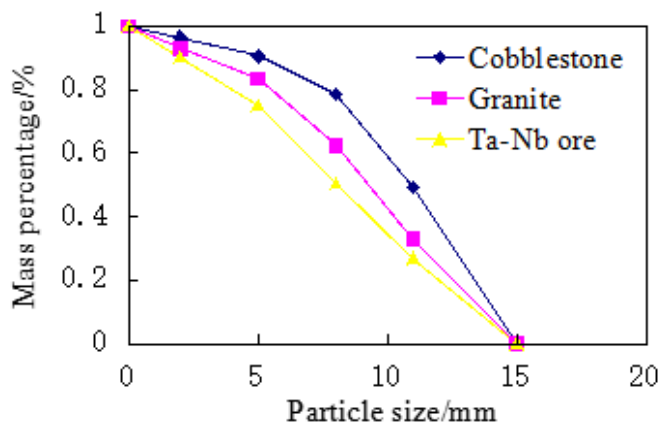

Figure 3. Fragment size distribution of three different rocks

It is described in logarithm with the data in Table 1 and the mass distribution in Formula (5). Then the data are fitted to obtain the relationship between the quality and the particle size distribution after rock being crushed, as shown in Figure 4:

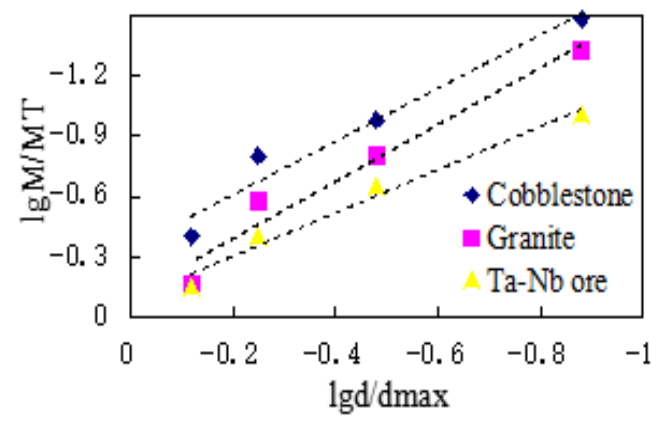

Figure 4. Mass and size distribution in logarithmic coordinates

Figure 4 shows the double logarithmic curves which are calculated based on the fractal dimension of three kinds of different rock size. It can be seen from the figure that a significant linear relationship between points indicates the crushed rock in the particle size distribution with good characteristics of fractal distribution. This feature will not change the type of rock. According to the relationship between the fractal dimension $D$ and the slope of the fitted line $K$, the fractal dimension is calculated with three rocks, as shown in Table 2. 


\section{MATEC Web of Conferences}

From Table 2, different fractal dimension $D$ is corresponding to different rocks because of the rock nature itself. In a sense, it characterizes the difference between rock properties within the material.

Table 2. Fractal dimension of the experiment

\begin{tabular}{llll}
\hline Ore & Cobblestone & Granite & Ta-Nb ore \\
\hline Linear fit K & 1.49 & 1.26 & 1.16 \\
Fractal dimension D & 1.51 & 1.74 & 1.84
\end{tabular}

4.2 Broken fractal dimension and broken index correlation analysis

In order to evaluate the crushing effect of pebbles, granite and the tantalum-niobium ore, the evaluation index of an average particle size, the yield below $8 \mathrm{~mm}$ and the broken rate are respectively calculated according to the data of Table 1 . The results are shown in Table 3:

Table 3. Different indexes for crushing

\begin{tabular}{llll}
\hline $\begin{array}{l}\text { Experiment } \\
\text { NO. }\end{array}$ & $\begin{array}{l}\text { The average particle } \\
\text { size/ } \mathrm{mm}\end{array}$ & $\begin{array}{l}\text { The yield } \\
\text { below } 8 \mathrm{~mm}\end{array}$ & $\begin{array}{l}\text { Broken } \\
\text { rate }\end{array}$ \\
\hline 1 & 10.22 & 0.215 & 0.40 \\
2 & 8.85 & 0.376 & 0.53 \\
3 & 8.12 & 0.446 & 0.57 \\
\hline
\end{tabular}

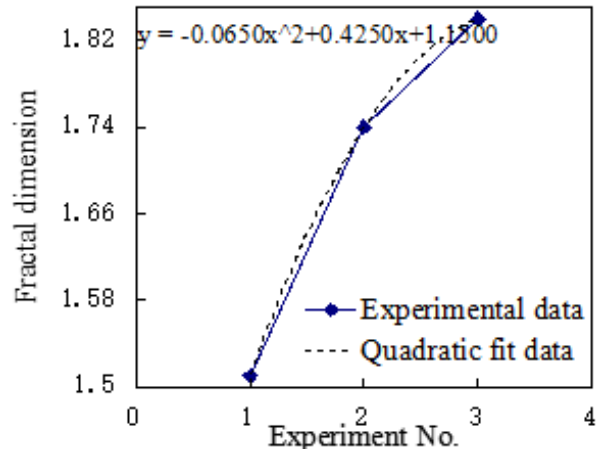

(a)

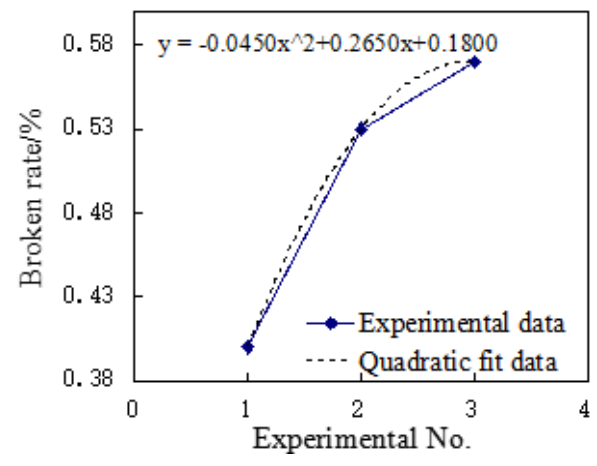

(b)

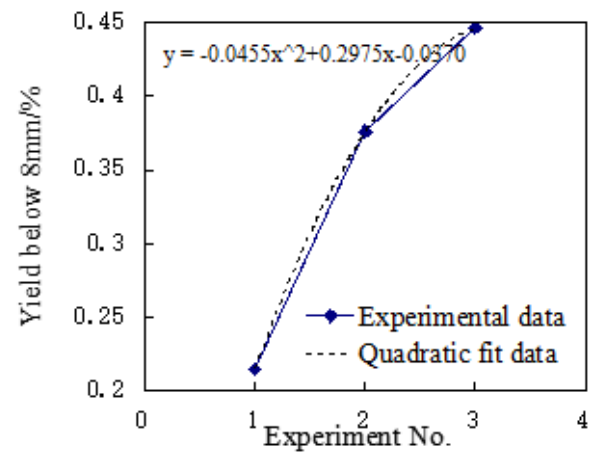

(c)

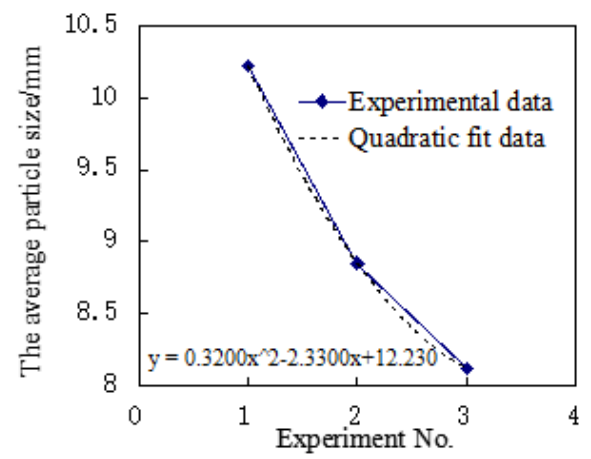

(d)

Figure 5. Relationship between the fractal dimension and the crushing index

The evaluation indexes of an average particle size, the yield below $8 \mathrm{~mm}$ and the broken rate are contrasted according to the different rock fractal dimension in Table 2. Four broken evaluation indexes of the size and trends are observed, as shown in Figure 5.

According to Figure 5, the crushed fractal dimension of three different types of rock is almost identical with the crushing rate of following 8 yield trends. The average particle size is just the opposite trend due to the description of the trend of the object in different directions. The result illustrates that the better the rock crusher is, the smaller the average particle size is; the greater the fragmentation rate is and the more yield below $8 \mathrm{~mm}$ is. The fractal dimension of crushing is also greater. The fractal dimension better illustrates that the evaluation of the fragmentation degree is consistent with several other traditional evaluation methods when after crushing.

\subsection{Fractal dimension relationship between the rock and the particle size}

In order to explore the fractal dimension of different primary particle sizes of the same kind of rock after being crushed, the tantalum and niobium ore rock experiments were conducted with particles whose 
diameters are respectively $18 \mathrm{~mm}, 21 \mathrm{~mm}, 24 \mathrm{~mm}$, $27 \mathrm{~mm}$ and $30 \mathrm{~mm}$. The particles carry out an extrusion crushing test on plate roller vibro-crosher, and the corresponding experimental groups were numbered as $1,2,3,4$ and 5 . The particle size of $\mathrm{Ta}-\mathrm{Nb}$ ore is respectively counted in the range of $<2 \mathrm{~mm}, 2-5 \mathrm{~mm}$, $5-8 \mathrm{~mm}, 8-11 \mathrm{~mm}$ and $>11 \mathrm{~mm}$. The mass fraction of $\mathrm{Ta}-\mathrm{Nb}$ ore is calculated after sieved using a standard sieve. The particle size distribution is shown in Figure 6:

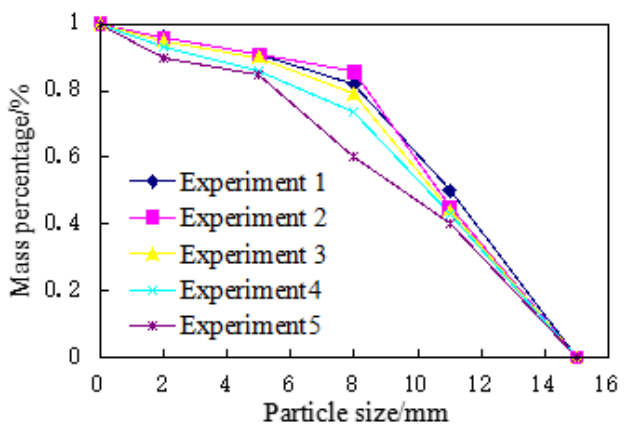

Figure 6. Fragment size distribution of tantalum niobium ore

Based on Figure 6, there are some changes about different particle sizes of tantalum and niobium ore rock after crushing. The larger the primary particles are, the fewer a large proportion of particle mass is and the more the yield of fine particle is. The particle size distribution of the crushed mass is calculated according to the method of fractal dimension. The fractal dimension is calculated for each group experiment. The data of each test are processed through energy detection device. According to the experiment data, the broken power is counted. According to the results of each broken experiment, we can respectively draw fractal dimension of different rock particles size of the tantalum and niobium ore. The fractal dimension of different tantalum and niobium ore and crushing energy is also drawn. The particle size curve is shown in Figures 7-8:

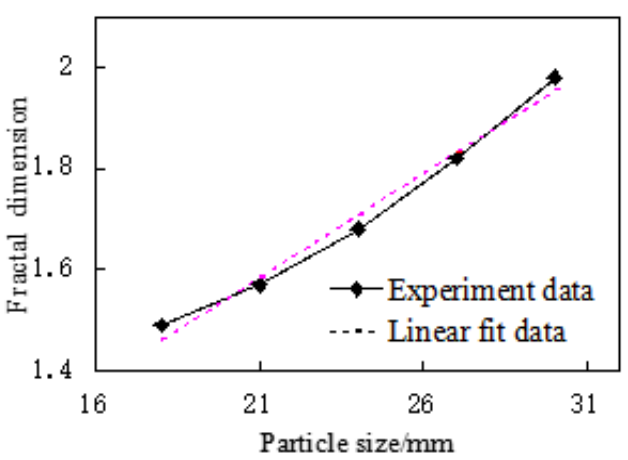

Figure 7. Relationship between the fractal dimension and the size

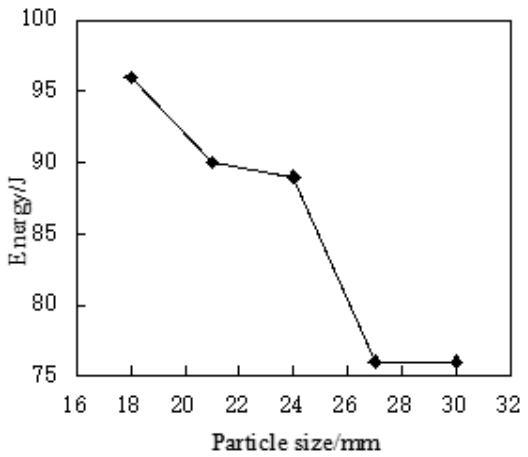

Figure 8. Relationship between the broken energy and the size

As can be seen from the chart, the fractal dimension represents an upward trend with the increase of the particle's diameter, and this is roughly a linear relationship. And we compare the broken particle size distribution chart, it shows that the greater the degree of particle breakage is, the greater the fractal dimension is. But the crushed fractal dimension increases, and the crushing effect is enhanced. As the energy of broken rock consumption is decreased, the approximate linear decrease gradually appears. This is because the rock particles are smaller, the particle agglomeration is closer, and then the rock defects of internal cracks are fewer. The more difficult it is to be broken, the more energy it is required when broken.

\section{CONCLUSION}

(1) Through analyzing three different particle sizes after pressing and crushing, this paper shows that the particle size distribution after crushing rock extrusion has fractal characteristics. Fractal characteristics are universal. What's more, fractal dimension can reflect the squeezing and broken effect well, which can be used as an indicator of broken evaluation.

(2) The extrusion crushing tests showed that due to the inherent properties, the broken fractal dimension of different rocks will be different after crushed. With the increase of particle size, the broken fractal dimension of the tantalum and niobium ore crushing rocks tends to increase, which is in the range of 1.5 to 2.0.

(3) With the reduction of rock particle diameter, its internal crack defects are less. And it is necessary to absorb more energy to make the rock cracks and expansion and eventually cause the fragmentation effect. Under the condition of absorbing energy, the fractal dimension of small particles which are produced after the rock being crushed is relatively small, and the degree of fragmentation is relatively low.

\section{ACKNOWLEDGEMENTS}

This work was supported by the National Science 


\section{MATEC Web of Conferences}

Foundation of China (No. 51464017) and the University Technology Building Plan Projects of Jiangxi Province, China (No. KJLD13045).

\section{REFERENCES}

[1] Zhu Hua. 2011. Fractal theory and its application. Beijing: Science Press,

[2] ZHENG Ke-hong, DU Chang-long, \& QIU Bing-jing. 2013. Experimental study on the fractal characteristics of crushing coal and gangue. Journal of coal, 38(6): 1089-1094.

[3] Xie H, \& Pariseau W G. 1993. Fractal character and mechanism of rock bursts. International of Rock Mechanism and Mining Science \& Geomechanics Abstracts, 30(4): 343-350

[4] WANG Wei, SU Jing-yu, \& MA Dong-hui, et al. 2012. Evaluation of rock mass quality based on fractal interpolation model. Journal of Central South University (Science and Technology), 43(12): 4827-4833.

[5] WANG Li, \& GAO Qian. 2007. Fragmentation Prediction of rock based on damage energy Dissipation. Journal of coal, 32(11): 1170-1174.

[6] WU Xian-zhen, LIU Xiang-xin, \& LIANG Zheng-zhao, et al. 2012. Experimental study of fractal dimension of $\mathrm{AE}$ serials of different rocks under uniaxial compression. Rock and Soil Mechanics, 33(12): 3561-3569.
[7] A. Tasdemir. 2009. Fractal evaluation of particle size distribution of chromites in different comminution environments. Minerals Engineering, 22(9):156-167.

[8] XU Jin-yu, \& LIU Shi. 2012. Research on fractal characteristics of marble fragments Subjected to impact loading. Rock and Soil Mechanics, 33(11):3225-3229

[9] WANG Li, \& GAO Qian. 2007. Fragmentation Distribution prediction of rock based on damage energy Dissipation. Journal of rock mechanics and engineering, 26(6):1202-1211.

[10]LIU Yu, ZHOU Jia-wei, \& DU Chang-long. 2014. Impact crushing probability difference between coal and gangue particles based on fractal theory. Vibration and shock, 45(9):2935-2940.

[11]LIU Yu, ZHOU Jia-wei, \& DU Chang-long. 2013. Fractal character of impact crushing granularity of coal lumps. Vibration and shock, 32 (3):18-21.

[12]Xie Peace. 1996. Fractal-Introduction to rock mechanics .Beijing: Science Press.

[13]ZHANG Ji-ru, ZHU Jie, \& HUANG Wen-jing. 2008. Crushing and fractal behaviors of quartz sand-gravel particles under Confined Compression. Journal of geotechnical Engineering, 30(6):783-789.

[14]M. Risnen, \& M Metamora. 2004. An evaluation of the procedure and results of laboratory crushing in quality assessment of rock aggregate raw materials. Bulletin of Engineering Geology and the Environment. 22(1):33-39. 